\title{
La emoción de una luz hecha a mano en arturo alvarez
}

Dr. Eugenio Rivas Herencia*

Universidad de Málaga

RECIBIDO: 02.11.2017 / ACEPTADO: 08.05.2018

\section{Resumen}

La marca de iluminación decorativa arturo alvarez se sitúa entre las más destacadas empresas de diseño a nivel internacional. La estrategia de su éxito radica en sus valores de respeto a lo natural junto con una fuerte apuesta por la innovación y la sostenibilidad. Su producción artesanal se combina con una potente apuesta de mercado.

Palabras clave: arturo alvarez, luz, iluminación de diseño, hecho a mano, simetech.

\section{The emotion of a handmade light by arturo alvarez}

\section{Abstract}

The decorative lighting brand arturo alvarez is among the most prominent international design companies. The strategy of its success lies in its frankly human values and a strong commitment to innovation and sustainability. Its handmade production is combined with a powerful market bet.

Keywords: arturo alvarez, light, design ilumination, handmade, simetech. 


\section{Arturo Álvarez y arturo alvarez: de la persona a la marca ${ }^{1}$}

Con más de dos décadas de plena dedicación al diseño y la producción de lámparas, arturo alvarez $z^{2}$ es en la actualidad una de las marcas españolas de iluminación decorativa con más proyección internacional. Algunas de las clasificaciones de mercado consideran a su fundador como uno de los diseñadores nacionales más relevantes del momento ${ }^{3}$. Arturo Álvarez es el fundador de la empresa y ejerce como director creativo, responsable de producto y diseñador principal.

La particular localización de la fábrica en un enclave natural es uno de los aspectos determinantes de la línea creativa de la marca. En la obra de Arturo Álvarez el entorno conforma una inagotable plataforma de referencias. El peso o el movimiento de sus luminarias parece muchas veces repetir el sinuoso ritmo del viento a través de los árboles o del mar en su encuentro con la roca. Es a partir de la naturaleza desde donde estos diseños gallegos descubren sus materiales, formas y texturas. Tal vez por ello, su centro logístico se mantiene en las afueras de Vedra, una localidad en la periferia de Santiago de Compostela. Una fábrica de luz en un entorno ideal para el recogimiento espiritual, un retiro creativo. Como el propio Álvarez declaraba para The Hedonist Magazine, las emociones atrapadas en sus lámparas nacen en la pequeña esquina verde de España. Esta experiencia, condensa en sus trabajos, pretende trasportar su peculiar universo al resto del mundo ${ }^{4}$. Quieren transmitir un modo de vida, un ritmo y una energía que emana de la naturaleza y de la calma del bosque atlántico que los rodea, pero que también es la de los habitantes del lugar. Esa conexión directa con el paisaje, esa escucha y observación de la naturaleza, parecen enraizadas en la creencia taoísta que busca la armonía en la resonancia entre el mundo que nos rodea y nuestro mundo interior. Desde la empresa se defiende con rotundidad que "si las lámparas de arturo alvarez son como son es precisamente porque nacen aquí. Si son únicas es porque beben de este paisaje, de esta cultura, de esta vida. Si son especiales es porque poseen una filosofía propia inseparable del medio en el que se crean"5. Todas estas influencias alimentan un proceso creativo que huye de modas o corrientes y se abre a la libertad de la mirada individual, al igual que la fenomenología, en una defensa de las manifestaciones concretas y un "regreso a las cosas mismas". Desde la perspectiva de Husserl, la obra de Álvarez, entendida como fenómeno que atiende a una intuición particular, se nos aparece y nos desvela por mera percepción sus cualidades esenciales ${ }^{6}$.

1 La marca es denominada con el nombre del diseñador escrito con letra minúscula y sin tilde en el apellido. Aunque la alusión es evidente, resulta importante diferenciar ciertos aspectos en los que la organización, a pesar de haber crecido sobre Arturo Álvarez, no se limita a su persona.

2 Desde principios de los noventa Arturo Álvarez (1964) ha experimentado diversas técnicas en la elaboración de lámparas. Sus inicios se centran en técnicas clásicas que con el tiempo dan lugar a una preocupación por nuevos materiales y estrategias creativas aplicadas a sus diseños.

3 Architonic. Architonic Top 100 Designers 2016/17, 2017 <https://www.architonic.com/en/story/architonic-architonic-top-100-designers-2016-17/7001566> (24.07.2017).

4 The Hedonist Magazine. Emotional Lighting, Interview Of Arturo Alvarez, $2016<$ http://www.thehedonistmagazine.com/2016/08/22/ interview-of-arturo-alvarez-emotional-lighting/> (24.07.2017).

5 ÁlVAREZ, A. Donde nace la luz, 2016 <http://www.arturo-alvarez.com/es/2016/07/donde-nace-la-luz> (07.08.2017).

6 VVAA. Conceptos fundamentales de filosofía, Alianza Editorial, 1998, p. 51. Husserl denominó a esta actitud perceptiva como "intuición eidética". En el texto se explica como este proceso intuitivo en el que se intuyen esencias comporta un proceso de conocimiento en el que "apartamos nuestra atención y ponemos entre paréntesis el mundo inmediato de nuestras percepciones espacio-temporales" y se procede con un modo de conocimiento no empírico. "En la reducción fenomenológica, nuestra conciencia intencional halla su correlato en lo dado de los datos de nuestra conciencia y se muestra así el carácter de algo dado que tienen las "cosas mismas" como objetos de la conciencia." 


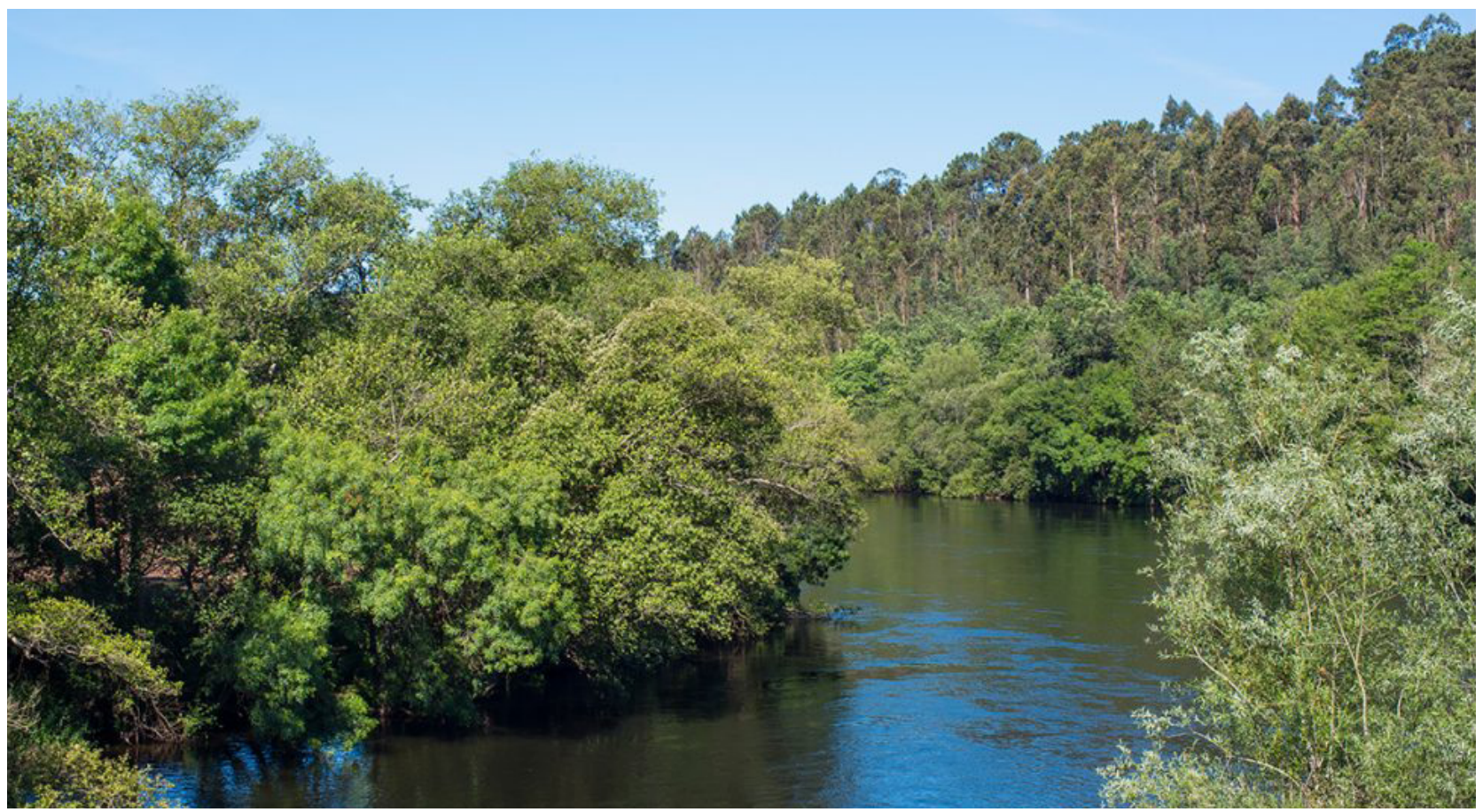

Fig. 1. Entorno natural de Vedra, cerca de Santiago de Compostela, Galicia. Fotografía de Héctor Santos.

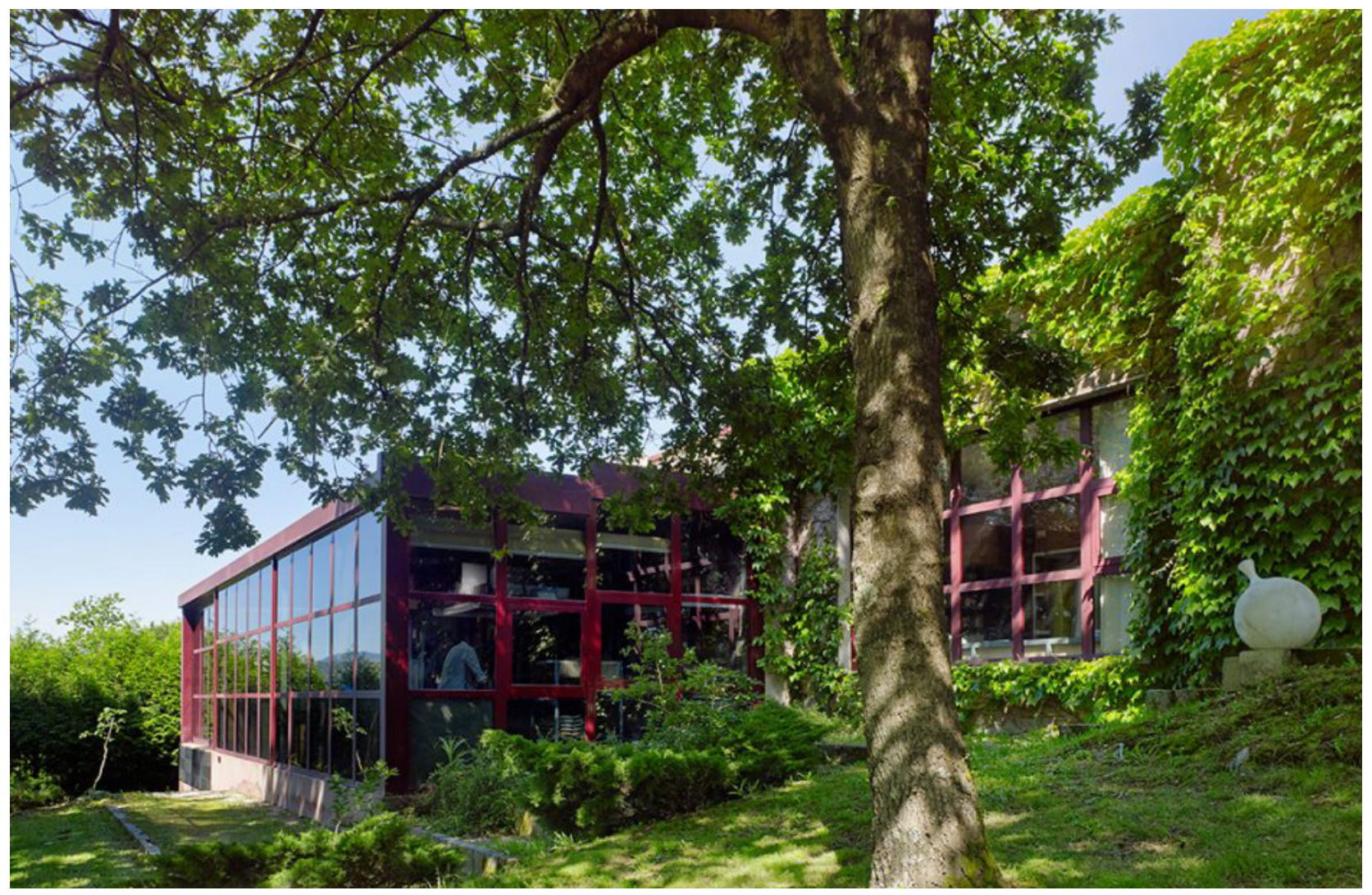

Fig. 2. Vista exterior del taller. Fotografía de Héctor Santos. 
El proceso creativo de Arturo Álvarez se mueve por la curiosidad que le lleva a explorar y descontextualizar elementos de lo cotidiano para concederles nuevos usos. Su condición autodidacta le aleja de prejuicios en la manipulación y las pruebas con cualquier tipo de materiales y objetos que encuentra a su alcance. En la entrevista publicada por Dis-up! Magazine comenta que su ejercicio creativo siempre ha consistido en "ver, experimentar, juntar, romper, mezclar materiales. Descontextualizarlos de sus usos habituales y conseguir, en el caso de las lámparas, juegos de claroscuros soportados por formas y volúmenes"7. Pero es importante señalar que para Álvarez el diseño posee ante todo un fin funcional. Por ello, sus propuestas aportan una nueva visión de la iluminación creativa con un doble objetivo, que apuesta también por un bienestar del ser humano ligado al disfrute hedonista del objeto. A su vez, defiende que el diseño trata de ayudar al máximo número de personas haciendo sus vidas más fáciles y confortables, pero esta idea no se traduce en la realidad de mercado de la empresa, ya que sus precios se sitúan fuera del alcance de la gran mayoría. En este contexto, cuando relacionamos los procesos creativos de la marca con el pensamiento taoísta por su sencillez, humanismo y defensa de la naturaleza, encontramos cierta contradicción, ya que en las enseñanzas de Lao Tsé se realiza una fuerte crítica al lujo, al deseo o al ejercicio del poder ${ }^{8}$.
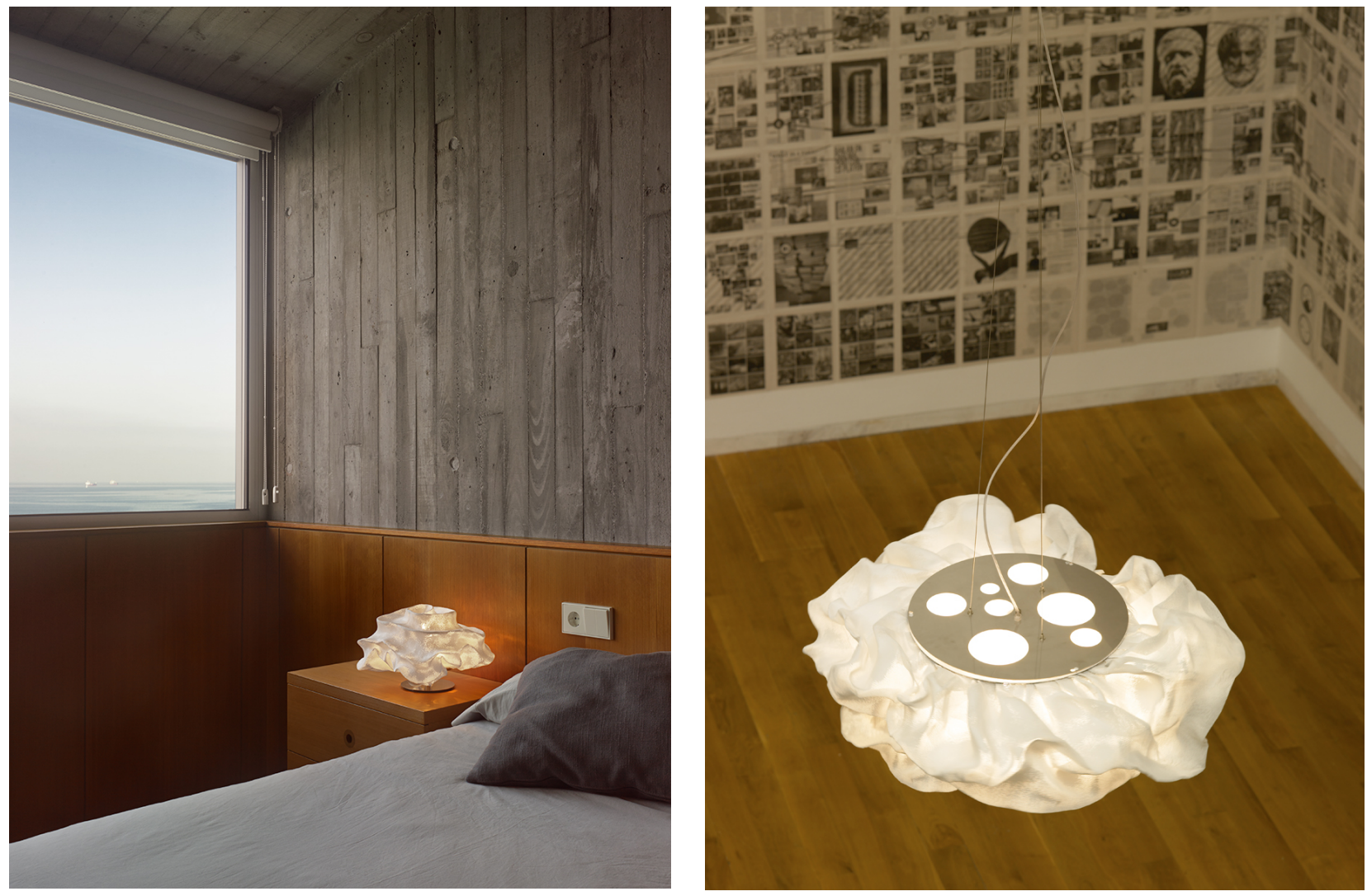

Fig. 3. Las lámparas de la serie Nevo presentan curvas modeladas a mano que recuerdan a los ritmos de la naturaleza. Cortesía de arturo alvarez*.

7 ÁlVAREZ, A. Donde nace la luz, 2016, Op. cit

8 GARCÍA, V. La sabiduría oriental: Taoísmo, budismo, confucianismo, Cincel, Madrid 1988, p. 156 


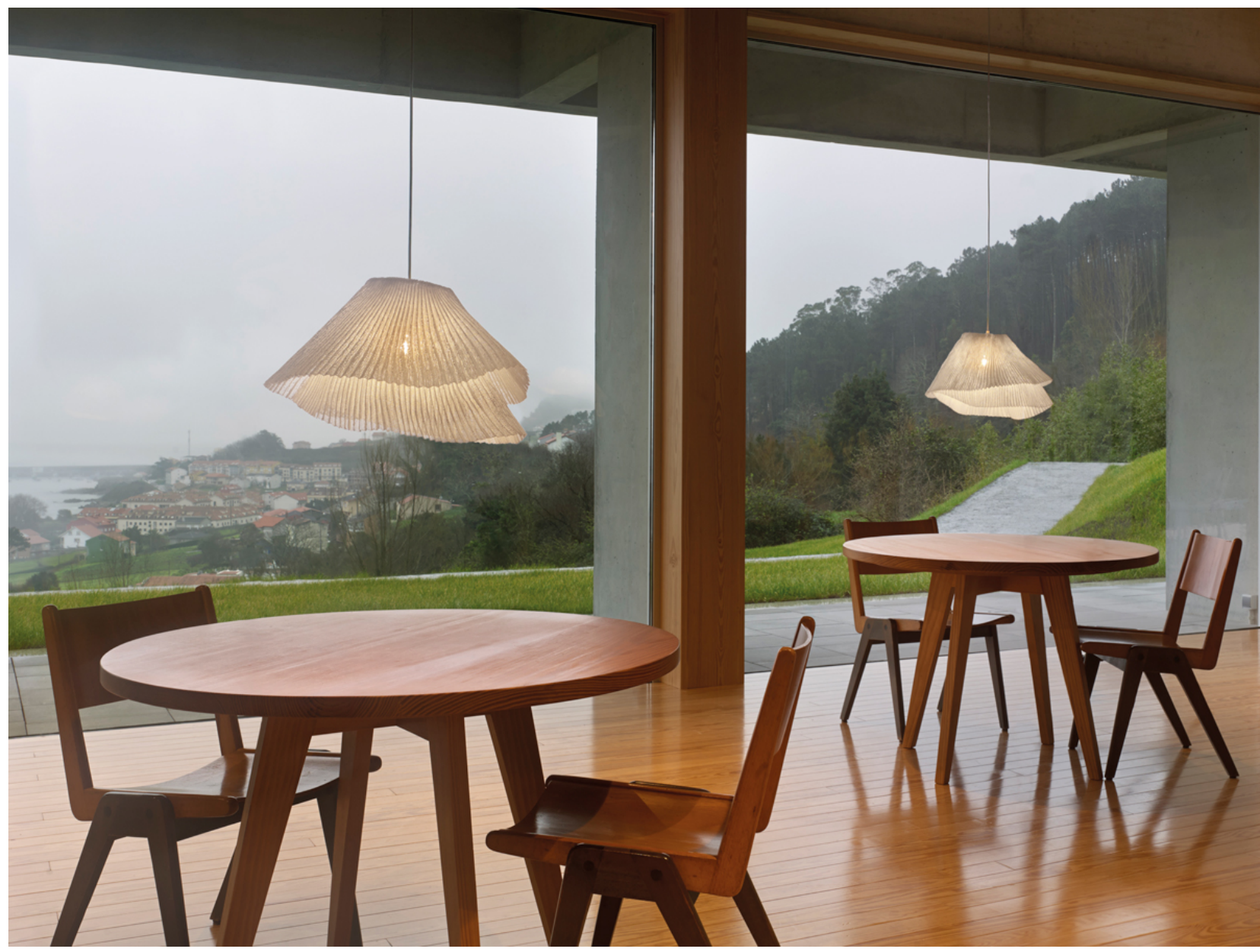

Fig.4.Tempo nos plantea una reflexión existencial atendiendo a los ritmos vitales. Cortesía de arturo alvarez.

\section{Cómo mantener la emoción a través del trabajo hecho a mano}

En la actualidad, como advierte el diseñador de interiores Arman Álvarez Lisenko, la iluminación va mucho más allá de su función básica de alumbrar. Es considerada un aspecto fundamental del espacio que junto a la arquitectura debe contemplarse a la hora de generar una sensación o determinar el uso, creando atmósferas que proporcionan experiencias únicas al usuario. Estos elementos son el resultado de un proceso creativo que constantemente explora el ambiente en busca de soluciones innovadoras. El éxito de la marca de Álvarez radica en una equilibrada relación que sus trabajos consiguen haciendo que espacio e iluminación hablen un mismo lenguaje, se influencien y se complementen mutuamente en una relación armónica9. La exclusividad de cada lámpara dota al objeto de un alto componente emocional. Un asunto que, como la marca se preocupa en aclarar, no compite con una fuerte experimentación y la implementación de nuevos materiales o el desarrollo de tecnologías que contribuyan al ahorro energético y a una producción sostenible. En este sentido, durante los últimos diez años la empresa ha realizado una labor exhaustiva de experimentación e

9 The Hedonist Magazine. Op. cit. 
investigación desarrollando unos materiales propios que le permitan mayor libertad creativa y expresiva. La labor de investigación condujo al desarrollo del Simetech ${ }^{\circledR 10}$, un material altamente moldeable, que en 2014 obtuvo el reconocimiento de BEST OFYEAR de Interior Design como mejor solución para iluminación.

Según defiende la empresa, en la actualidad su preocupación por el medio ambiente y respeto al planeta le llevan a abandonar todos aquellos materiales que no son biodegradables, una cuestión que Álvarez aborda como un asunto de conciencia social.Y por ello, el ahorro energético y la iluminación LED están cada vez más presentes en su trabajo. Sin embargo, entre sus materiales más usados se pueden destacar el hilo y la malla de acero inoxidable pintados, el polipropileno, el vidrio, el tablero marino y la celulosa prensada, que en su versión de cordón es el único recurso que la empresa especifica como reciclado. No existen evidencias de un plan de sostenibilidad u otras pruebas que demuestren un compromiso en este sentido. Tampoco sus últimos diseños hacen gala de ese cambio que la empresa defiende estar llevando a cabo.
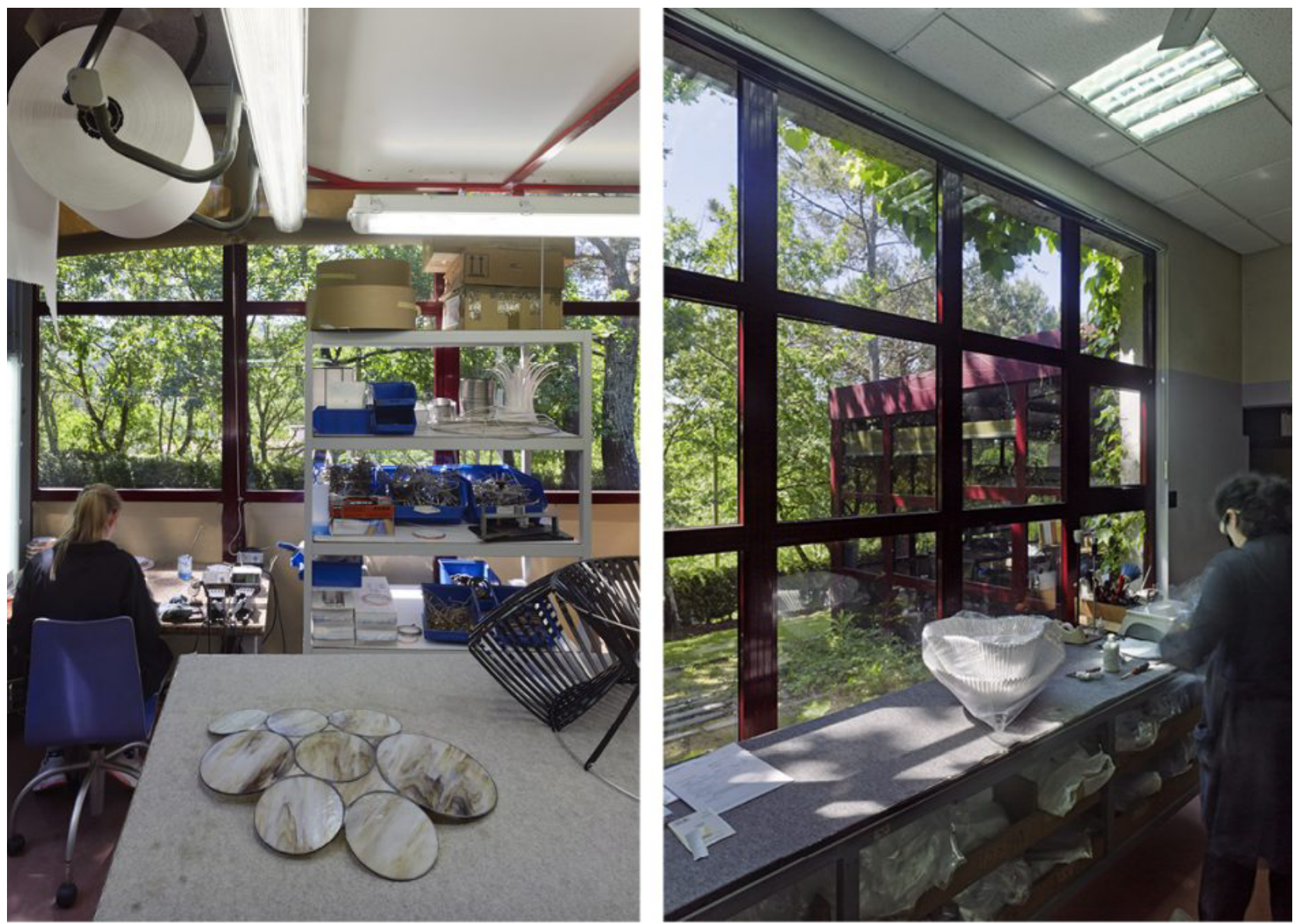

Fig.5. Taller arturo alvarez. Fotografía de Hector Santos.

Por otro lado, entre los valores principales que definen a arturo alvarez cabe destacar el carácter de lo forjado a mano, la singularidad y la personalidad que son el fruto de un minucioso trabajo. Respecto a sus

10 Simetech $\circledast$ es un material translúcido realizado con malla metálica y un acabado de silicona desarrollado y patentado por arturo alvarez, que puede ser modelado fácilmente para la obtención de diferentes formas y texturas. 
procedimientos, la empresa confiesa haber aprendido de cada uno de los oficios tradicionales que los rodean. Se trata de una apuesta por el desarrollo local sin dar la espalda a la tradición y al buen hacer de sus gentes ${ }^{11}$. La producción íntegramente manual, que bebe de la artesanía de la zona, se convierte así en un valor de marca. Esta forma de trabajar, junto con la pasión, la sensibilidad y la creatividad envuelven la identidad de arturo alvarez y hacen de cada uno de sus productos una luz emocional, como promete su eslogan emotional light ${ }^{12}$. En la propia web se defiende que la razón de ser de la empresa consiste en generar emociones por medio de cada diseño: "La premisa: siente, disfruta, libérate, apasiónate, sueña, pero sobre todo... EMOCIÓNATE!"13.

Como escribiera Gastón Bachelard en La poética del espacio, la fenomenología de la imaginación es la encargada de captar el ser efímero. Es en tal brevedad donde se alimenta la acción fenomenológica, un proceso metafísico que nace como fruto de la experiencia contemplativa y turba la noción de espacialidad al tiempo que abre las puertas de la imaginación ${ }^{14}$. También Sergio Givone respalda este razonamiento cuando, revisando a Hartmann, defiende que lo artístico atiende a la intuición más que a la instrucción. Nos recuerda que la tradición ha concebido al poeta como "el que ve" (vates), como aquel a cuyo testimonio es posible apelar después de siglos. En este sentido insiste en que "la esencia del objeto bello no está en lo que aparece, sino en el aparecer mismo; este aparecer de golpe eleva la materia [...] por encima del reino de la apariencia y le muestra al que lo contempla algo que en la vida no encuentra"15.

Para Álvarez, es la emoción la que dota de vida al objeto inanimado y genera un aura a su alrededor que nos conduce a un estado de ilusión y bienestar. De esta clara intención poética deducimos cierta devoción por la sencillez. En ese gusto por lo mínimo puede adivinarse una dimensión moral que, como el arquitecto John Pawson defiende, implica desinterés e idealismo. Una noción que desde diferentes culturas ha sido considerada como "una virtud capaz de purificar el espíritu y de ofrecer a los creyentes una sensación de paz interior"16. Esta eliminación de lo sobrante en busca de la esencia y la perfección entronca igualmente con la noción del wabi, la búsqueda de la pobreza voluntaria. "El wabi -aclara Pawson- es un principio moral y estético que aboga por una vida de quietud y por el retiro del mundo. Valora la belleza de lo simple y lo austero, al tiempo que busca la serenidad y la trascendencia que la acompaña." Y nos demuestra que el exceso se convierte en carga y nos hace dependientes, mientras que la ausencia nos proporciona el espacio necesario para la comprensión y el entendimiento ${ }^{17}$.

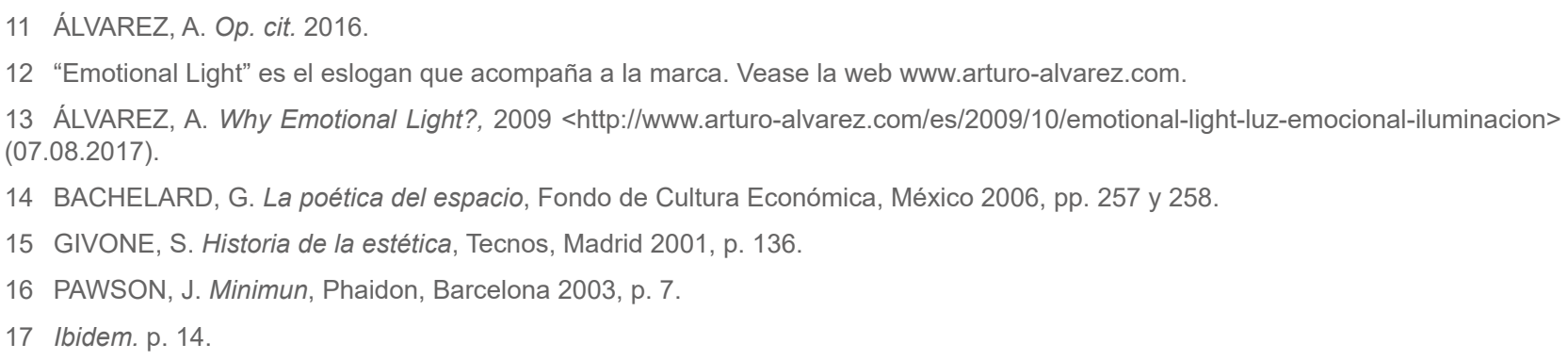




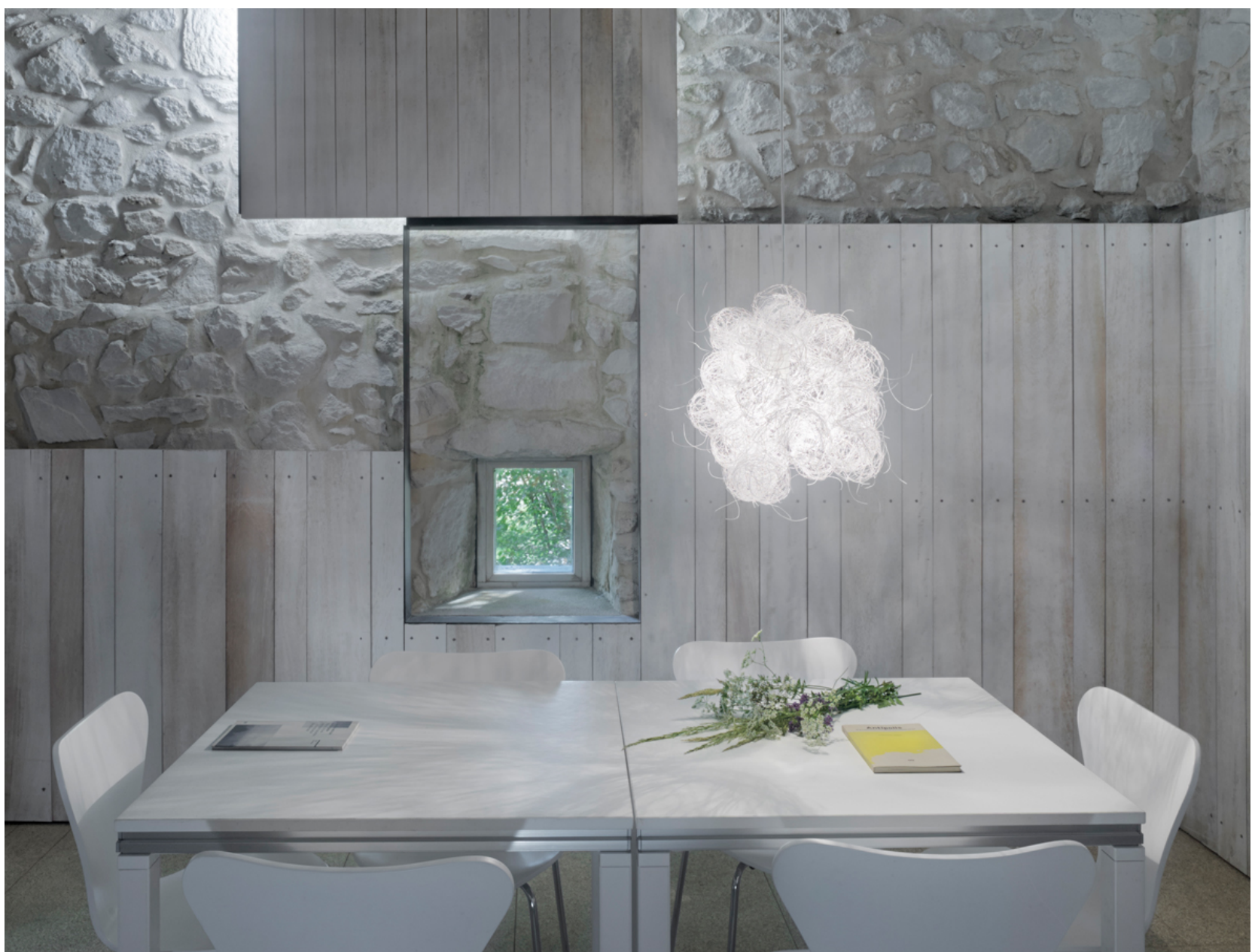

Fig.6. El diseño Blum seduce con su orden caótico. Está realizada con hilo de acero inoxidable pintado. Cortesía de arturo alvarez.

\section{Las sombras y su luz. La sensibilidad oriental de arturo alvarez}

Atendiendo a los procedimientos y estrategias de producción de arturo alvarez resulta ineludible traer a colación algunas de las ideas fundamentales que Junichirō Tanizaki recogiera en su reconocido texto El elogio de la sombra. El gusto del diseñador en el uso de recursos para difuminar la luz coinciden con el deleite de Tanizaki ante el juego de sombras producido por una bombilla solitaria tras los shõji de una granja ${ }^{18}$. La luz, su sombra, cómo ambas dialogan con el espacio y lo configuran junto a la arquitectura son los factores que establecen esta ecuación emocional.

Entre los variados asuntos que Tanizaki afronta en su lúcido texto, plantea la reflexión de que si oriente hubiese

18 TANIZAKI, J. El elogio de la sombra, Siruela, Madrid 2016, pp. 8 y 9. El autor introduce una nota al pie donde aclara el termino shōji: "Tabique móvil formado por una armadura de listones de cuadrículas apretadas, sobre la que se pega un papel blanco grueso que deja pasar la luz, pero no la vista. Los shōji eran hasta hace poco el único cerramiento de la casa japonesa. Por la noche, les añaden otros tabiques (amado), también corredizos. Hoy en día, los shōji suelen estar precedidos, o incluso sustituidos, por puertas acristaladas". 
seguido su propio ritmo y dirección, en lugar de adoptar la mentalidad occidental, eventualmente se hubiesen encontrado soluciones radicalmente diferentes. Ante este planteamiento podríamos pensar que "los propios principios de la física y de la química, considerados bajo un ángulo distinto al de los occidentales, habría tenido aspectos muy diferentes a los que hoy en día se nos enseña en lo que respecta, por ejemplo, a la naturaleza y las propiedades de la luz, de la electricidad o del átomo"19. Tal vez por ello, el estilo japonés, sus gustos, soluciones o formas, relucen de un modo peculiar. Partiendo de un antiguo artículo, Tanizaki nos plantea una hipótesis en la que pudiéramos suponer que el creador de la estilográfica hubiese sido japonés o chino. No cabría duda de que en lugar de la punta de una plumilla hubiera situado un pincel. Y en lugar de tinta azul, habría colocado algún tipo de líquido parecido a la tinta china. Esto, junto con el desarrollo del papel, hubiera provocado el auge de los ideogramas y la escritura silábica de los kana, desfavoreciendo a su vez el eco de los caracteres latinos. Con esta digresión Tanizaki muestra que "la forma de un instrumento aparentemente insignificante puede tener repercusiones infinitas"20.

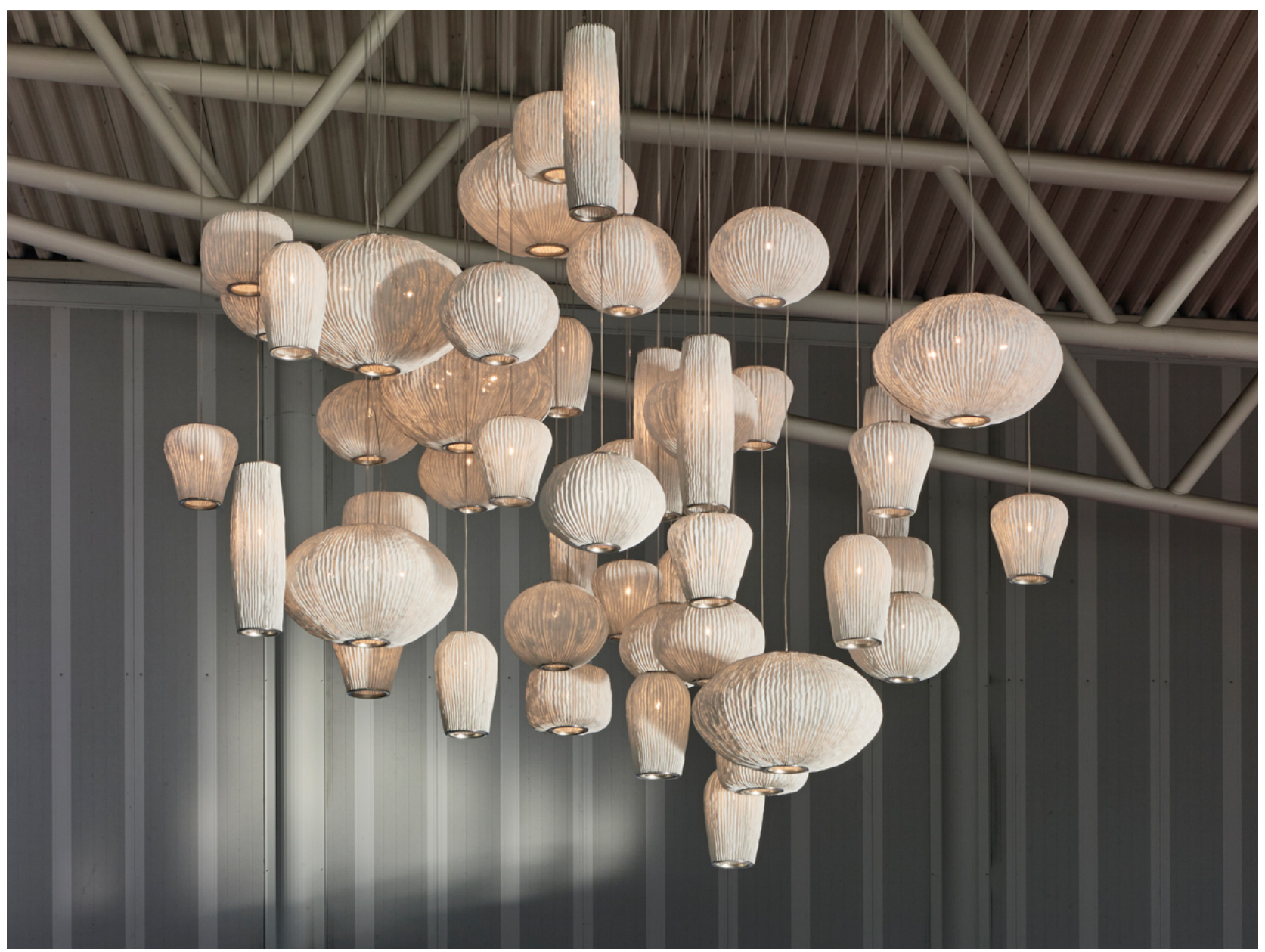

Fig.7. Composición de la colección de lámparas colgantes Coral. Cortesía de arturo alvarez.

19 Ibidem. p. 20.

20 Ibidem. pp. 21 y 22. Artículo publicado en los Bungei-shunju (Amantes del Arte literario), revista fundada en 1923 por el escritor Kikuchi Kan. 
A partir de esta suposición podemos deducir que la falta de prejuicios de Álvarez, su individualidad y alejamiento de escuelas o tendencias dota a sus trabajos de un carácter genuino que podría aproximarse a la sensibilidad oriental. En esta dirección podemos plantear ciertas conexiones con la serie de luces Akari del escultor y diseñador nipo-estadounidense Isamu Noguchi. En ella el autor sigue un camino aparentemente simple que surge a partir de una visita de Noguchi a Japón a principios de la década de 1950. Elizabeth Wildhide destaca la unión de dos perspectivas, una técnica y otra poética. Esta serie de lámparas nace a partir de un viaje en el que Noguchi coincide con unos pescadores nocturnos que realizan su labor en el río Nagara a la luz de faroles de papel, llamados cochin, fabricados en la zona, en la ciudad de Gifu. La incorporeidad de aquellos faroles flotando sobre el agua produce una gran seducción en el diseñador que, a partir de aquel momento fabrica sus lámparas Akari siguiendo un proceso tradicional y manual en el que pega papel de corteza de morera sobre un ligero esqueleto de bambú ensamblado sobre un armazón de alambre. Según Wildehide "las lámparas de Noguchi recurren al principio de difusión para crear esculturas iluminadas en las que la luz parece flotar sin lastre e ir a la deriva del espacio"21. Una sensación que se impone igualmente ante prácticamente cualquier diseño de arturo alvarez. La ligereza de la luz hace que los elementos que componen cada lámpara parezcan flotar en el espacio iluminado.

Tal vez Oriente, si se le hubiese dejado mantener su propio paso, mucho más atento al ritmo de la naturaleza, podría haber desarrollado una civilización igualmente avanzada mucho más conforme a su propio mundo con soluciones adaptadas a sus propias necesidades. Hasta en la música podemos advertir cierta contención, debido a la importancia que se le concede al ambiente. En ella se evitan los gritos, se cultivan las elipsis y, por encima de todo, se le otorga una tremenda importancia a las pausas. "Ahora bien —precisa Tanizakiesa luz indirecta y difusa es el elemento esencial de la belleza de nuestras residencias. Y para que esta luz gastada, atenuada, precaria, impregne totalmente las paredes de la vivienda, pintamos a propósito con colores neutros esas paredes enlucidas". Ya que "si brillaran se desvanecería todo el encanto sutil y discreto de esa escasa luz"22. El japonés elogia la profundidad, la sobriedad y la densidad de los objetos a la luz única de una lámpara de aceite o de una vela. Algo que nunca sucederá bajo la luz solar directa o una iluminación intensa. Toda esta atmósfera de incierta claridad, ese espacio umbrío, incita discretamente a la ensoñación, donde los parpadeos de la llama parecen latidos de la noche. "Los rayos de luz, como delgados hilos de agua que corren sobre las esteras para formar una superficie estancada, son captados uno aquí, otro allá, y luego se propagan, tenues, inciertos y centelleantes, tejiendo sobre la trama de la noche un damasco hecho con dibujos dorados"23. Y como en una decoración dorada, la luz se transparenta en las lámparas de arturo alvarez, se difumina a través de las capas o se filtra colándose entre los pequeños huecos del aplaudido Simetech ${ }$, donde la alta tecnología se pone al servicio de un modelado manual para generar sinuosas formas en un seductor juego de transparencias.

\footnotetext{
21 WILDHIDE, E. Cómo diseñar una lámpara, Gustavo Gili, Barcelona 2012, pp. 17 y 18.

22 TANIZAKI, J. Op. cit. pp. 43 y 44 .

23 Ibidem. pp. 34 y 35.
} 


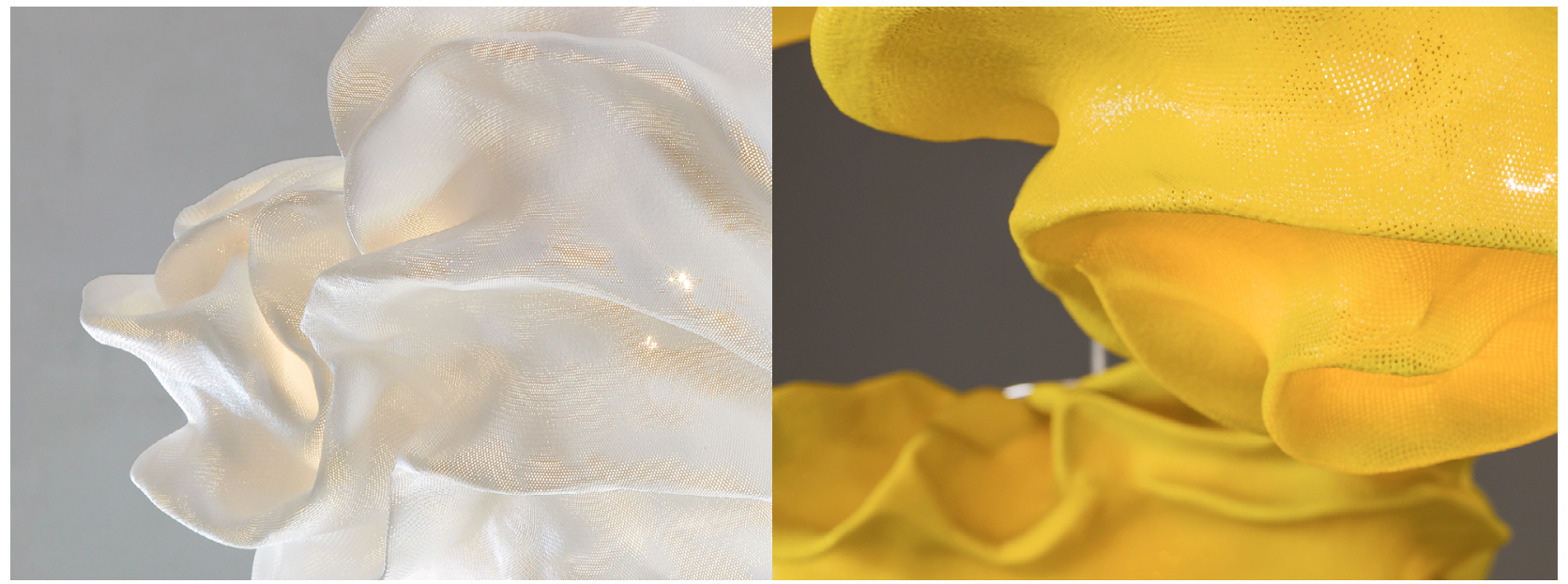

Fig.8. Detalles de lámparas diseñadas con Simetech®. Cortesía de arturo alvarez.

Ante las luminarias de arturo alvarez descubrimos gratamente que dicha sensibilidad no ha quedado recluida en las fronteras de oriente y desde el norte peninsular descubrimos ese universo ambiguo donde sombra y luz establecen un juego de sugerencias. Para Tanizaki el misterio reside en saber resignarse, "que la luz es pobre, ipues que lo sea!, es más, nos hundimos con deleite en las tinieblas y les encontramos una belleza particular"24. En lugar de experimentar repulsión ante la adversidad es posible entenderla como una opción única llena de sus propias ventajas, tal y como ocurre en el taller de arturo alvarez.
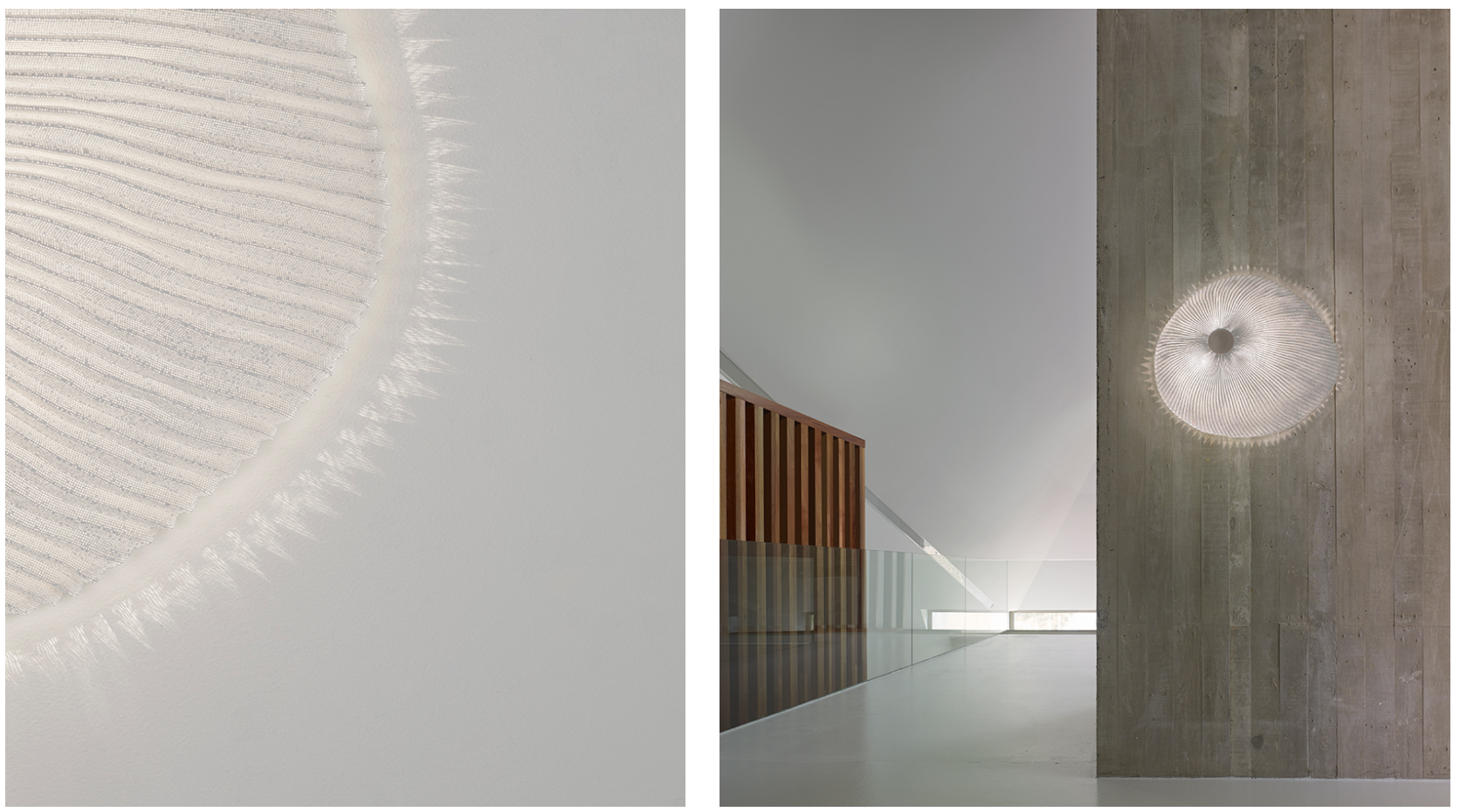

Fig.9. Colección Onn. Cortesía de arturo alvarez. 


\section{De cara al futuro. El presente de la iluminación}

La empresa se plantea continuar con su apuesta por la investigación, con la intención de desarrollar nuevos materiales para sus diseños y, al mismo tiempo, mantener su preocupación por la implementación de tecnologías que contribuyan al ahorro energético y a una producción sostenible. Tras la significativa creación y patente del Simetech ${ }^{\circledR}$, Álvarez confiesa que sigue trabajando con hilo japonés y alambre de acero. La curiosidad por poner las cosas al límite y su obsesión por el perfeccionismo son los motores que le llevan a prestar especial atención a la luminosidad y los claroscuros, a la creación de un ambiente acogedor y, al tiempo, romper con toda limitación en la solución formal de sus productos.

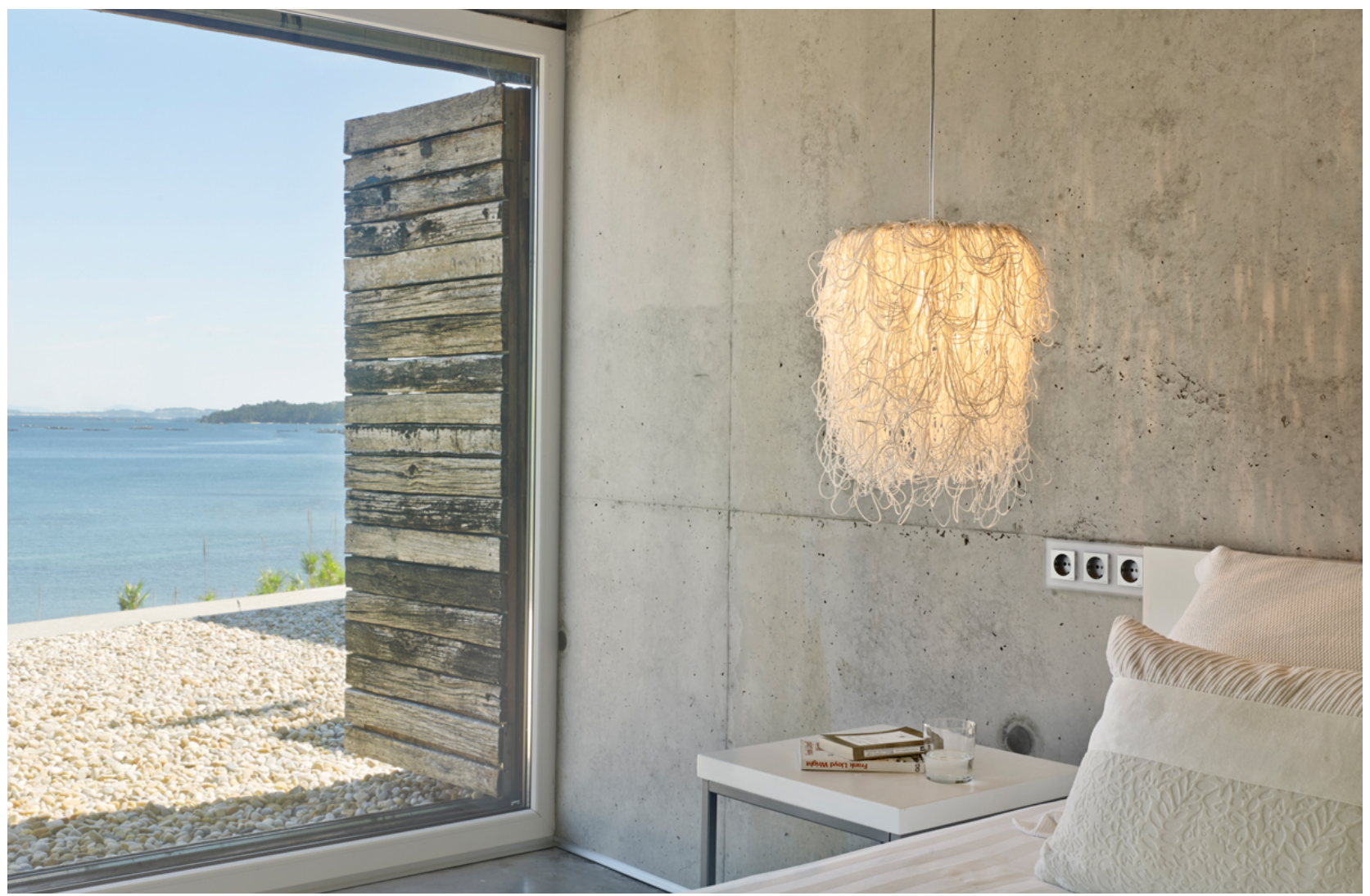

Fig. 10. Caos usa para su construcción cordón de celulosa reciclado. Cortesía de arturo alvarez.

Debido al giro conservador de la industria del diseño causado por la presente situación económica, en la actualidad las propuestas son menos arriesgadas y audaces, declaraba Álvarez para The Hedonist Magazine ${ }^{25}$. Esto conlleva una consecuencia positiva, el filtro natural de todo lo superfluo y lo prescindible. El futuro tiene como objetivo principal el ahorro energético, el reciclaje y el respeto por el medio ambiente. Todo ello, sin perder de vista que los hábitos de los consumidores, en relación con las nuevas tecnologías, están cada día más presentes en el diseño actual ${ }^{26}$. 
En su entrevista a Dis-up! Magazine, el diseñador confesaba que desde una perspectiva comercial las verdaderas claves para avanzar con éxito en el diseño y producción de luminaria consisten en "Ser honesto contigo mismo, buscar la creatividad en todo momento, trabajar mucho, investigar y rodearte de un buen equipo. Y sobre todo, intentar tener un estilo propio diferenciado y ser fiel a él"27. Sin embargo, su enfoque comercial no se limita a una actitud creativa e incansable. Su público objetivo se centra cada vez más en grandes clientes como hoteles, restaurantes y oficinas; donde el nivel de exigencia hace que sus proyectos sean apreciados por su buen diseño, calidad y exclusividad. De este modo, se completa la estrategia de mercado de una empresa que cimenta su identidad sobre valores humanos.

\section{Bibliografía y referencias documentales}

ÁLVAREZ, A. Donde nace la luz, 2016 <http://www.arturo-alvarez.com/es/2016/07/donde-nace-la-luz> (07.08.2017).

ÁLVAREZ, A. Tres maestros de la iluminación que transforman el diseño en arte, 2017 <http://www.arturo-alvarez.com/es/2017/10/tres-maestros-de-la-iluminacion-que-transforman-el-diseno-en-arte> (02/10/2017).

ÁLVAREZ, A. Why Emotional Light?, 2009 <http://www.arturo-alvarez.com/es/2009/10/emotional-light-luz-emocional-iluminacion> $(07.08 .2017)$.

"Architonic Top 100 Designers 2016/17" en Architonic , 2017 <https://www.architonic.com/en/story/architonic-architonic-top-100-designers-2016-17/7001566> (24.07.2017).

"Three Illumination Masters Turn Lights into Works of Art" en Azure, 2017 <http://www.azuremagazine.com/ article/artistic-merit/> (22.09.2017).

BACHELARD, G. La poética del espacio, Fondo de Cultura Económica, México 2006.

"Arturo Alvarez" en Darc Magazine , 2015 <http://www.darcmagazine.com/arturo-alvarez/> (07.08.2017).

DARVY, P. Feng shui. Conocimientos antiguos para la vida moderna, Barcelona, Blume 2007.

"Entrevista al creador autodidacta de objetos de iluminación, Arturo Álvarez" en Dis-Up! Magazine, 2017 < http://www.disup.com/entrevista-arturo-alvarez/> (07.08.2017).

GIVONE, S. Historia de la estética, Tecnos, Madrid 2001.

GARCÍA, V. La sabiduría oriental: Taoísmo, budismo, confucianismo, Cincel, Madrid 1988.

MARTíNEZ, P. arturo alvarez 20 years, 2014 <http://www.arturo-alvarez.com/es/2014/02/arturo-alvarez-20-years> (04.09.2017)

PAWSON, J. Minimun, Phaidon, Barcelona 2003.

TANIZAKI, J. El elogio de la sombra, Siruela, Madrid 2016.

27 Dis-Up! Magazine. Op. cit. 
The Hedonist Magazine. "Emotional Lighting, Interview Of Arturo Alvarez", $2016<$ http://www.thehedonistmagazine.com/2016/08/22/interview-of-arturo-alvarez-emotional-lighting/> (24.07.2017).

WILDHIDE, E. Cómo diseñar una lámpara, Gustavo Gili, Barcelona 2012.

VVAA. Conceptos fundamentales de filosofía, Alianza Editorial, Madrid 1998. 